\title{
The Teaching Reform of History of Journalism Based on Communication Effect
}

\author{
Teaching Method of Keywords
}

\author{
Xiaorui Li \\ Mianyang Teachers' College \\ Mianyang, China
}

\author{
Xuya Wang \\ Mianyang Teachers' College \\ Mianyang, China
}

\begin{abstract}
As a special kind of communication activity, classroom teaching activity is one of the means to test the classroom teaching. Rethinking the teaching of news history from the perspective of communication effect will be helpful to the reform of the teaching methods. This paper gives an exploratory summary of the concept of key words teaching method, and illustrates the application and propagation effect of the teaching method in practice.
\end{abstract}

Keywords—communication effect; teaching method; keywords; teaching reform

\section{INTRODUCTION}

As the basic course of journalism major, journalism history course plays an important role in the professional training program. Ono Kinobita, the first person of Japanese journalism and communication, and the first director of the journalism institute at the University of Tokyo said that in any news and communication faculty professional settings, there are three subject positions unshakable, one of which is the journalism history course. And Pan Jiaqing, a professor at the School of Journalism and Communication at the National Chengchi University, also said that journalism history should be one of the six core courses in journalism education. [1] There are many historians who hold this view; therefore, it is self-evident that the journalism majors learn the history of journalism.

At the same time, in the daily teaching and learning, we are not difficult to find that large span of time, many knowledge points, wide coverage, relatively independent knowledge points, and difficult contact memory. In this case, most students have low interest in the study and poor learning effect. Therefore, in view of journalism history learning is irreplaceable, and in order to better solve the many universal problems existing in the teaching and learning of journalism history, it is necessary to further analyze and discuss the reform of journalism history course in undergraduate colleges and universities on the basis of the spreading effect.

\section{THE IMPORTANCE OF REFORMING THE TEACHING METHODS OF NEWS HISTORY FROM THE PERSPECTIVE OF COMMUNICATION EFFECTS}

In the field of communication, the communication effect is a double concept, one of which is the change of psychology, attitude and behavior caused by the communication behavior with the persuasive motive. The effect of communication on the effectiveness of communication activities is an intuitive presentation, so it plays an important role in the evaluation of communication activities. And our teaching activities, like news reports, are a complete process of communication. Therefore, the disseminator, the communication channel and the audience have a great influence on the final communication effect of this teaching activity. In the process, the influence of teachers as a communicator on teaching and broadcasting activities is self-evident, and our way of teaching is like a communication channel. It plays a role in linking teachers and students, and directly affects the effectiveness of teaching and communication activities. Therefore, from the perspective of the communication effect of teaching activities, we will focus on the influence of teaching methods on the effect of communication.

In view of the current educational models of journalism history in universities, the vast majority still use the traditional teaching methods of cramming education. The teachers lecture, students listen to the teaching content, the teaching content is also carried out in accordance with the compilation of textbooks, although there are many deficiencies, however, at present, it still fails to explore a more appropriate teaching methods of journalism history. To investigate the reasons, there are some deficiencies, whether our communicators teachers or communication channels - teaching methods. Therefore, the author tries to explore a way of teaching the history of journalism in colleges and universities in order to benefit the teaching of the subject.

\section{CONCEPT AND IMPLEMENTATION PROCESS OF KEYWORD TEACHING METHOD}

\section{A. The Origin of the Keyword Teaching Method}

The keyword is derived from the vocabulary in library science. The inspiration of keyword teaching method is based on author's Internet search. Keyword search is one of the main ways to network search index, and the advantage of data retrieval is direct, accurate and wide correlation, which can make the audience get more useful information. Therefore, taking into account the problems in the study of journalism history: there are many knowledge points and they appear to 
be independent and interrelated, the author finds that it is helpful to improve the teaching effect and the students ' learning efficiency by quoting the keyword search method into the teaching of news history, and which can effectively improve such problems in journalism history learning.

\section{B. The Concept of Keyword Teaching Method}

The author thinks that keyword teaching method refers to an effective teaching method that determines the key words in the teaching process, establishes some links between knowledge points around the selected keywords, and forms visual illustrations and clear network as the main content. The first step of keyword teaching method is to select 1-2 keywords according to the teaching content. The second step is to establish the internal relation between the knowledge points and the selected keywords. The third is to focus on the relevant knowledge points to expand and extend, enrich the content of the teaching and increase the students' knowledge. In this teaching method, the important and difficult point is to establish the relevance of knowledge points, so as to build the internal network of the related knowledge modules.

\section{The Implementation Process of Keyword Teaching Method}

The use of key words teaching method focuses on helping students to relate knowledge points and flexible memorization through visual representation and the establishment of clear network. The advantage of this method is that students can build their own keyword learning mode according to their own learning habits.

In the third chapter of the History of Chinese News Communication, the author takes the Rise and Development of the Newspaper as an example to elaborate the concrete implementation process of "key words" teaching method. This chapter mainly involves: (a) the Chinese people's understanding of the early modern newspapers and periodicals. (b) Chinese people's news ideology: the conception of news and the formation of news ideas of Hong Renxuan, Wang Xi, Zheng Guanying, etc. (c) the first Chinese newspaper: the characteristics of running conditions, the Reformists founded the Circular Daily and a number of magazines and newspapers to develop (innovations in journalism, trials of news legislation) newspaper development influence and so on. Compared with other chapters, the content of this chapter in addition to need more memorizing basic knowledge points, knowledge points are closely linked, it is easier to select keywords when using the keyword pedagogy. It is easier to select keywords when using the keyword pedagogy.

According to the traditional teaching method, the teaching of the contents of this chapter will be long and the focus is not outstanding, the students' memory is shallow and easy to forget. If the key words teaching method is used to teach the knowledge point of this chapter, the original teaching order will be subverted, and the difficulty will be more clear.

Before this chapter is taught, the first thing to be prepared is to determine the keywords of each section. The choice of keywords should follow certain principles.
1) amiliar with principles.

The choice of keywords is the first and most important step of this teaching method, so it is necessary to follow the familiar principles of students when choosing the vocabulary. Only select students more familiar with the words, to better mobilize the enthusiasm of students to further study, also facilitate students remember the words, for the next study to lay the good foundation.

\section{2) Relevance principle}

Another principle of keyword selection is relevance. That is to say, the selected keywords need strong relevance with other knowledge points in this chapter, so that it can occupy the core position in the teaching process, play the role of bridge, and connect more knowledge points.

After detailed analysis of the knowledge in this chapter, following the above guidelines, we design the keywords network of this chapter as "Fig. 1" and "Fig. 2":

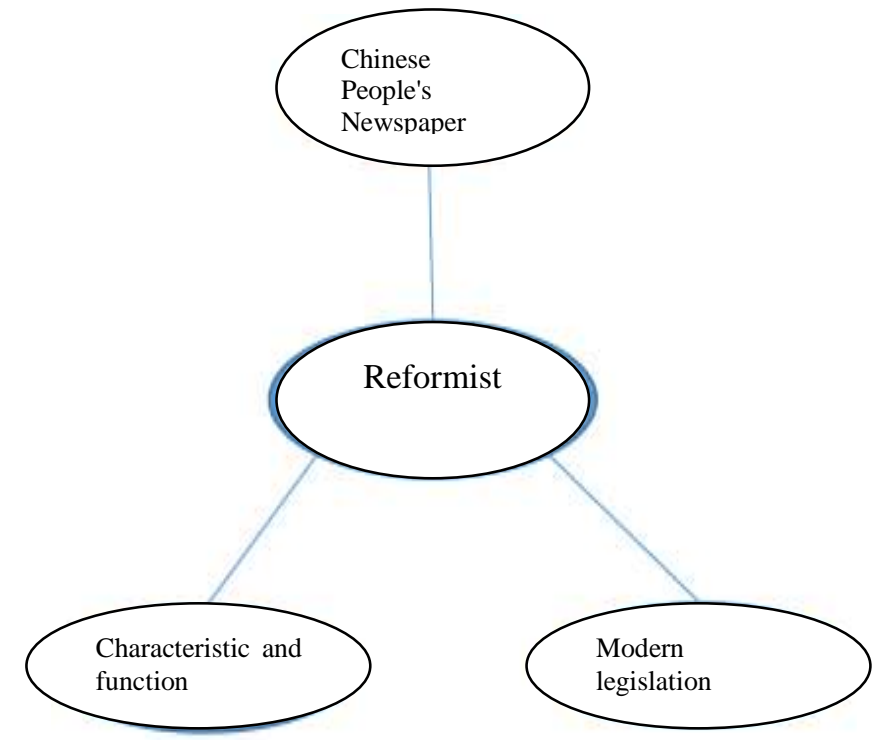

Fig. 1. The structure diagram with the keyword "Reformist".

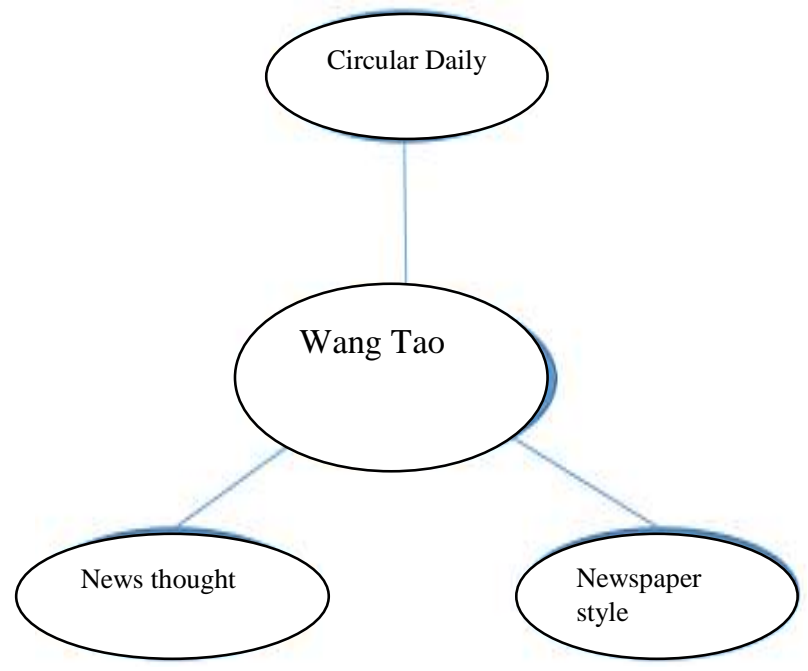

Fig. 2. The structure diagram with the keyword "Wang Tao". 
In these two diagrams, the middle word is "keyword" and the surrounding area is related knowledge point. The author will make a brief explanation of this teaching method by taking "Fig. 2" as an example. The first is the selection of the keyword "Wang Tao". Wang tao is a famous newspaper and political commentator in the history of Chinese journalism, which is familiar to students and conforms to the principle of selecting key words. And according to this selected keyword, the knowledge points are extended in three directions. First, the Circular Daily, which he founded, has a great influence in the newspaper industry at that time. It is the first newspaper in China that advocated bourgeois political reformism and the earliest Chinese Daily written by Chinese. Therefore, this knowledge will be connected with the content of "Chinese People's Newspaper" in "Fig. 1". The second is the newspaper style that has been used in this newspaper. Its characteristics and background are also the key points in this chapter. The third is news ideology. Although Wang Tao was not the first person to expound the concept of journalism in the history of Chinese journalism, his concept of journalism has a distinct era and advanced nature in the historical context at that time. The knowledge points that can be associated with it are: Hong Rengan, Zheng Guanying and news thoughts of other early newspaperman.

On the order of teaching, the teacher taught first keyword content, after teaching related knowledge, also can teach keywords by teachers, students' self-study and show related knowledge.

\section{ANALYSIS OF TEACHING EFFECT OF KEYWORD TEACHING METHOD}

The key word teaching method in journalism history teaching is based on the importance of journalism history learning and the poor dissemination effect of traditional teaching methods. It has strong pertinence and achieves better teaching results in the practical teaching of journalism history.

\section{A. It Is Helpful to Improve Learning Interest}

Compared with the traditional learning method, the key word teaching method can well mobilize the enthusiasm of students to participate in learning. Only by converting passive learning into active learning, can students' learning enthusiasm change significantly, and the learning effect can be improved. The students of Henan University of Science and Technology have done a survey on the factors that affect college students' learning motivation. According to their findings, up to $87 \%$ of college students admit that "if they like a teacher's lectures, they will go to class actively."[3] The keyword teaching method is different from the traditional teaching method. This teaching method can reflect the teachers' thinking and attention to teaching, which can bring students the motivation to learn. In the selected vocabulary can also be given to students for familiarity with knowledge, thus closer to students' psychological distance, also can better reflect the different of keyword teaching methods, it is easier to enhance the enthusiasm of students to participate in learning, which is to achieve good teaching effect and lay a solid foundation.

\section{B. Help to Highlight the Key Points}

One of the characteristics of the key words teaching method is to show the relevance of knowledge points by means of graphic representation. The students can directly judge the key knowledge, while in the teaching process; the teacher will also clearly show the key knowledge part in the time allocation. Therefore, students have a clear definition of key knowledge in the first place, and in the following study, they will also allocate their energy and time well to optimize the teaching effect.

\section{It Helps to Enlarge the Scope of Knowledge.}

In the process of preparing lessons, teachers can not only complete the preparation of related contents independently, but also assign tasks to students in class. The second way is to hand over the task of collecting information to everyone. In this way, it not only changes learning from passivity to initiative, but also strengthens students' ability of information collection, and increases the increase of knowledge into a possibility.

\section{THE REQUiREMENT OF KeYWORds TEACHING MethoD FOR TEACHERS}

As the soul of teaching communication activities, teachers are very important for the formation of good teaching effect, and the implementation of keywords teaching method also puts forward higher requirements for teachers themselves. First of all, teachers should constantly improve their professional knowledge reserves. To a certain extent, keywords teaching method will improve students' enthusiasm, and active thinking in depth will participate in the process of learning, so teachers should have the knowledge to deal with the needs of the student's knowledge were growing.

Second, the teacher should carefully design the keyword architecture diagram. The design of the keyword architecture diagram is related to whether the whole teaching method can be carried out smoothly and whether it can guarantee the maximization of communication effect. Therefore, a lot of requirements are put forward for the teachers. First, understand the audience. That is, teachers should have a certain understanding of the students in the class, especially their interest in learning. In the stage of higher education, due to the complexity and diversity of professional education, students' individual differences are especially prominent. On the basis of understanding the teaching objects, teachers should study teaching methods so as to follow the inherent rules of teaching.[2] Second, teachers should be familiar with the teaching content. Only on the basis of familiarity with the content of teaching, teachers can find the relevance of knowledge points so as to accurately select effective keywords. Thirdly, teachers should carefully design after-school questions. After class, the question is not only an extension of classroom teaching, but also a test of the learning effect of students. However, in many cases, the after-school thinking questions become a kind of learning burden for students, because it cannot continue the students' interest and enthusiasm in learning. Therefore, teachers should not only consider the test function to the maximum, but also consider whether students can accept it. 


\section{CONCLUSION}

Keyword teaching method has many advantages for journalistic history teaching, but it doesn't mean that all chapters are suitable for teaching with this method, nor is it required for teachers to abandon traditional teachingmethods.Because keyword teaching method has high requirements for the internal relations of chapter knowledge points. For the content with high knowledge independence, teachers should adopt traditional teaching methods or other more appropriate ways to achieve the purpose of teaching. Therefore, teachers should not blindly use this teaching method and forcibly establish the connection of knowledge points, which in turn makes it easier for students to learn to create obstacles that affect the effectiveness of teaching activities.

\section{REFERENCES}

[1] Pan Jiaqing. Difficulties in the Study of Journalism History, International Press J. 2004, No. 4:9.

[2] Zhang Yongsheng, Zhang Manman et al. Analysis of Factors Affecting College Students' Learning Motivation, Journal of Henan University of Science and Technology, February, $2016: 43$.

[3] Guo Mingjie. The Application of Feature Teaching Method in Journalism History Teaching, Journal of Hubei University of Arts and Sciences, June, 2012:81. 